\title{
COMMUNICATIVE CONDITIONALITY OF SPEECH ANOMALIES IN THE PRESENT-DAY PUBLIC DISCOURSE
}

\author{
Elena I. Pochtar \\ Pridnestrovian State University named after T.G. Shevchenko, Tiraspol, Pridnestrovian Moldavian Republic
}

\begin{abstract}
The article deals with the consequences of influence caused by socially conditioned extra linguistic phenomena on the language policy in present-day national communities, and with the issue of keeping language norms and conventions in speech communication. Comparing the language system with its original openness and variability, on the one hand, and the language norm characterized by its conservatism and rigid regulations, on the other, the author detects a basic contradiction between these two, which reflects upon ways of organizing communication in today's societies. It is proved in the article that when speech behavior of most communicators is conditioned by ethnocultural, moral-ethic, and pragmatic-commercial specificities, appearance of various linguistic irregularities in public discourse becomes unavoidable. The author classifies language norm violations into two categories: unconscious and conscious, individually viewing the cases of positive and negative communicative effects caused by language anomalies. Based on the analysis of the examples of conscious deviations detected in advertising as a typical variation of present-day public discourse, the article reveals a variety of forms of language anomalies in the pragmatically oriented text, as well as their high degree of communicative effectiveness. The author also makes a suggestion that the scale of deviative phenomena in speech practices of world communities will extend in the near future.

Key words: communicative competence, language norm, language system, speech anomaly, irregularity, language deviation, advertising discourse, nonstandard form of presenting information.

УДК $81 ’ 271.12$

Дата поступления статьи: 23.09.2016

ББК 81.025

Дата принятия статьи: 28.10.2016
\end{abstract}

\section{КОММУНИКАТИВНАЯ ОБУСЛОВЛЕННОСТЬ РЕЧЕВЫХ АНОМАЛИЙ В СОВРЕМЕННОМ ОБЩЕСТВЕННОМ ДИСКУРСЕ}

\author{
Елена Ивановна Почтарь \\ Приднестровский государственный университет им. Т.Г. Шевченко, г. Тирасполь, Приднестровье
}

\begin{abstract}
Аннотация. В статье рассматриваются последствия влияния социально обусловленных экстралингвистических явлений на языковую политику современных мировых национальных сообществ и возникающая в связи с этим проблема соблюдения в речевой коммуникации языковых норм и конвенций. Сопоставляя языковую систему с ее природной открытостью и вариативностью и языковую норму, характеризующуюся консерватизмом и жестким регламентом, автор приходит к выводу о наличии между ними базисного противоречия, отражающегося на организации коммуникационного пространства современных социумов. В статье доказано то, что в условиях, когда речевое поведение большинства коммуникаторов обусловливается этнокультурной, морально-этической и прагматически-коммерческой спецификой организации коммуникативного пространства, возникновение в общественном дискурсе разного рода языковых иррегулярностей становится неизбежным. Нарушения норм языка автор делит на две категории: неосознаваемые и осознанные, отдельно останавливаясь на случаях, когда языковые аномалии вызывают положительный и отрицательный коммуникативные эффекты. На основе анализа примеров осознанных девиаций, обнаруженных в рекламе как типичной разновидности современного общественного дискурса, в статье выявлены разнообразие форм языковых аномалий в прагматически ориентированном тексте и высокая степень их коммуникативной эффективности. Автор также высказывает предположение о том, что в ближайшем будущем масштаб девиативных явлений в речевых практиках мировых социумов будет увеличиваться.
\end{abstract}


Ключевые слова: коммуникативная компетентность, языковая норма, система языка, речевая аномалия, иррегулярность, языковая девиация, рекламный дискурс, нестандартная форма подачи информации.

1

Тесная взаимосвязь между языковыми и социальными тенденциями находит свое отражение в 50-60-е гг. XX в. в развитии двух ключевых направлений социально ориентированного подхода к языку: социолингвистики и социологии языка. Обе науки принципиально сходятся в том, что трансформационные процессы, происходящие в обществе, прямо или косвенно влияют на языковое варьирование в отдельно взятых социальных средах и нередко определяют языковую ситуацию в целом.

Рассматриваемое в социолингвистическом аспекте речевое поведение личности есть прямое выражение ее коммуникативной компетентности, которая, согласно Д. Хаймсу, трактуется как интуитивное знание говорящим принципов использования языка и умение контролировать применение этих принципов в процессе речевой деятельности [9, с. 119]. Расширяя описанное Н. Хомским [7] понятие лингвистической компетентности, включающее преимущественно языковые знания и умения, при определении коммуникативной компетентности ученые делают акцент на уместности использования языка, не умаляя при этом важности знания его грамматики. Как постулирует Д. Хаймс, владение языком - это в том числе умение определять, «когда говорить, а когда нет, что говорить и кому, когда, где и в каком виде» [8, с. 277].

Коммуникативная, или социолингвистическая, компетентность позволяет человеку адекватно формулировать и воспринимать речевые послания в зависимости от ситуации общения, выбранной темы и характера взаимоотношений между участниками общения. Не менее важными элементами этой компетентности являются знания о сакральном, о культурных табу, об эксплицитных и имплицитных моделях речевой имплементации социальной иерархии, общеупотребительных способах проявления вежливости и корректности, дружелюбия, обходительности, иронии и других морально-этических основ организации социума, неизбежно манифестируемых в языке.
2

Социолингвистический подход к анализу изменений последних лет в языковой политике и речевой практике множества мировых национальных сообществ позволяет обнаружить их тесную связь с масштабной геополитической, этнографической и этнокультурной реорганизацией в современном мироустройстве. Последствия влияния социальных факторов на трансформации в речевом поведении наиболее заметны в области реализации языковой, или литературной, нормы.

Нарушения языковых стандартов можно считать в некоторой степени предопределенными спецификой языковой системы, ее природной открытостью, внутренней неоднородностью и функциональным разнообразием, которые выступают в качестве благоприятных факторов возникновения в языке разного рода «колебаний, вариантов, дуплетов и прямых неправильностей» [5, с. 278].

При этом возникает противоречие, когда неправильности, аномалии, иррегулярности, девиации ${ }^{1}$, с одной стороны, провоцируются отсутствием в языке жестких, непроницаемых границ, с другой - они же нарушают целостность его системы, выходя за рамки сформировавшегося единства языка, его устоявшихся парадигм [3; 4].

Неизбежность возникновения в речи отклонений от языковой нормы, их многочисленность и разнообразие форм не означают тем не менее, что любые факты речевой асистемности суть явления бесконтрольные и беспорядочные.

Исследуя проблему речевых аномалий, необходимо вспомнить, что все они, так или иначе, выступают в качестве оппозиции языковой нормативности. Под языковой, или литературной, нормой, как правило, понимается набор языковых средств, тщательно отобранных из общего единства естественного языка, а также свод правил, призванных обеспечить их стандартное употребление во всех формах общественного дискурса. Важной особенностью нормы является то, что составля- 
ющие ее языковые средства и правила сознательно отобраны и апробированы обществом, затем зафиксированы в качестве традиционных моделей использования языка. Иными словами, нормативной базой языка являются общепризнанные языковые шаблоны, «сознательно культивируемые и сохраняемые социумом в качестве неотъемлемого атрибута языка как средства коммуникации» [5, с. 285]. Этот ключевой аспект стандартизации моделей языка акцентируется и британским лингвистом Т. МакАртуром, описывающим языковую норму как «стандарт, модель... общепринятого использования языка» [10, с. 704].

В силу своей общепризнанности литературная норма должна гарантировать социуму этически и психологически здоровый вербальный климат с понятными, общедоступными и единообразными стандартами ведения коммуникации. Тем не менее практическая сложность реализации этой цели, а также специфика коммуникативных функций большинства современных публичных дискурсов приводят к тому, что предписанные языковые конвенции нарушаются массово и повсеместно.

В значительной степени это провоцируется самой природой языковой нормы, ее константностью и консерватизмом, жесткостью ее границ. Эти параметры нормы вынуждают ее вступать в противоречие с перманентно меняющимся жизненным пространством социума, его мобильностью, динамизмом, стремлением к эволюции и индивидуальности самовыражения.

\section{3}

К типичным нарушениям языковых стандартов относятся многочисленные речевые аномалии, настолько широко употребляемые в социумах, что их анормальность перестает идентифицироваться как таковая. Сюда относятся разного рода грамматически неверные формы и конструкции, алогичные речевые обороты, окказионализмы и прочие относительно устойчивые и распространенные отклонения от языковых норм. Например, в англоязычной речевой практике приемлемым считается использование местоимений третьего лица множественного числа they, them, their по отношению к существительному единственного чис- ла в случаях, если гендерная принадлежность названного ими субъекта не определена или предполагает варианты (определение его как мужчины и как женщины). Несмотря на явное несоответствие нормам грамматики, такое употребление стало общепринятым: Every attendant was ready to give their hand of help to the poor woman. Nobody wants to let go of what is sacred for them. В то же время такие лексические единицы, как unbeautiful, headful, вполне укладывающиеся в рамки нормативного английского словообразования, на практике воспринимаются как примеры окказиональной лексики и, следовательно, являются аномальными в понимании среднестатистического носителя английского языка.

Количество оппозиций и антиномий на стыке языковых норм и речевых практик значительно возрастает при анализе региональных вариантов английского языка. Например, dreamt - форма прошедшего времени глагола dream («спать, мечтать») - нормативна в британском варианте английского языка, но аномальна в американском английском, и наобоpoт, dreamed, использующаяся в качестве нормативной в американском варианте английского языка, считается девиацией в британском английском.

Будучи системным явлением, нарушающим лексические и грамматические нормы языка, девиации могут возникать на всех уровнях: фонологическом, морфологическом, синтаксическом, семантическом и прагматическом. Важную роль при этом играет позиция языка в общемировой языковой ситуации. Английский язык как один из основных международных языков-посредников используется в качестве средства общения многомиллионными коллективами не-носителей языка и, следовательно, обнаруживает более масштабные отклонения в сфере реализации языковых норм, нежели многие другие языки мира.

\section{4}

В зависимости от степени отклонения речевых форм от общепринятых ожиданий рецептивной аудитории речевые аномалии могут иметь как отрицательный, так и положительный коммуникативный эффект. Отрицательное воздействие характерно для ситу- 
аций, когда речевые иррегулярности нарушают основополагающие фонетические, грамматические и лексические каноны языка.

Типичными примерами фонетических аномалий в английском языке являются слова, при произнесении которых искажаются отдельные звуки или сочетания звуков (например, answer - [answo] вместо [ansə]), нарушаются правила ударения или интонирования слов, синтагм и целых предложений (например, hotel - ['hotel] вместо [hau'tel]). При том что фонетические отклонения создают сильный негативный эффект при восприятии, гораздо большее отторжение у рецептора вызывают аномалии грамматические (например, John gived me a wrong address; I'm stay with my friend's family; We were so exciting after watching this film; He always want be the first) и лексические (например, He carred his friends to the station; It only depends from you; What we need is a concrete answer to our question). Отрицательный коммуникативный эффект этих девиаций обусловлен тем, что они нарушают существующие речевые традиции и порождают тем самым в подсознании рецептора настороженность, отчуждение, неприятие.

Основными факторами таких отклонений от языковой нормы являются недостаточная грамотность говорящего либо его иноязычное происхождение, а также индивидуальная речевая небрежность, психосоматическое, этико-социальное или этнокультурное своеобразие личности коммуникатора.

\section{5}

К речевым аномалиям, вызывающим положительный коммуникативный эффект, относятся отклонения от речевых конвенций, целенаправленно создаваемые и применяющиеся говорящим для реализации заданных прагматических намерений. В отличие от первой категории аномалий, провоцирующих отрицательный эффект при восприятии и, как правило, возникающих спонтанно, неосознанно, отклонения второго типа, несущие прагматический заряд, вводятся коммуникатором в речь сознательно и вызывают эмоциональное восприятие с неизменно положительным коммуникативным эффектом. Ярким примером владения искусством осознанных девиаций может служить известный оксюморон Джорджа Оруэлла «война - это мир, свобода - рабство, незнание - сила». В этом высказывании целенаправленное нарушение языковых норм путем создания смыслового парадокса, очевидно, выполняет прагматические задачи привлечения внимания, создания интриги, мотивации читателя к сложной процедуре декодирования скрытых смыслов и посланий на имплицитном уровне искусно созданного речевого диссонанса.

Такие нестандартные формы подачи прагматической информации, именуемые в лингвостилистике образными языковыми средствами, или стилистическими приемами, составляют основную массу речевых иррегулярностей, широко представленных в целом ряде современных дискурсов, реализующих функции воздействия, и прежде всего, функцию убеждения. К дискурсам, в рамках которых активно используются осознанные девиации в виде стилистических выразительных средств, относятся публицистика, реклама, художественная проза, публичное ораторство и многие другие. Благодаря своей нестандартности и неожиданности средства и приемы языковой выразительности не только делают речь привлекательной, но и «позволяют значительно увеличить информационную емкость текста», так как создаваемые ими образы реферируют к широкому диапазону фоновых знаний адресата, его культурному коду, морально-нравственным, этическим и эстетическим парадигмам [1, с. 49].

Масштаб осознанных девиаций в современных публичных дискурсах настолько велик, что, перефразируя оксюморон Джорджа Оруэлла, можно утверждать: анормальность сегодня стала обыденностью, неожиданность - привычностью, нестандартность - нормой.

\section{6}

Говоря непосредственно о формах речевой манифестации осознанных анормальностей, отметим, что наиболее употребительны множественные вариации языковой игры. Как показано в исследовании Л.А. Кочетовой, роль игровой составляющей в рекламном дискурсе значительно возросла в последние десяти- 
летия и по частотности превосходит употребление других стилистических приемов [2, c. 133]. По мнению ученого, это объясняется тем, что языковая игра способна наиболее успешно реализовать функциональный потенциал рекламного дискурса, так как она «маскирует воздействие и стирает границы между развлечением и рекламой» [2, с. 133]. При этом в отличие от других стилистических приемов, большей частью использующихся для привлечения внимания, языковая игра имеет «неоспоримое коммуникативное преимущество» в силу того, что она активирует когнитивные способности адресата-интерпретатора и вовлекает его в коммуникативный процесс ментально и эмоционально [2, с. 133].

Среди множества форм языковой игры, создающих эффект парадокса, наиболее распространенными, по данным проведенного нами исследования, являются лексические окказионализмы, каламбуры всех языковых уровней, стилистические диссонансы и стилевые контрасты [6].

Примером окказиональной формы создания осознанной игровой девиации может служить лексема repairwear в рекламе крема для лица торговой марки «Clinique». Представленный окказионализм состоит из двух стандартных лексических единиц: repair («чинить, ремонтировать») и wear («носить, носка»), которые соединены в единую лексему по типичной для английского языка модели словосложения $\mathrm{N}+\mathrm{N}$, характерной для таких стандартных английских сложных слов, как footwear («обувь»), sportswear («спортивная одежда») и т. д. Лексическая девиация repairwear своей нестандартностью, очевидно, реализует прагматические задачи привлечения внимания и создания интриги, в свою очередь повышающих эффективность воздействия имплицитного послания: - «Крем Clinique “исправит / починит” все шероховатости и несовершенства вашего лица».

Нарушая стандарты словообразования и словоупотребления, окказиональная лексика в рекламе создает эффекты энигматичности и неожиданности, способствующие привлечению внимания и усилению интриги. По этой причине большое количество окказиональных форм языковых девиаций обнаруживается в рекламных брендах. Так, в рекламном тек- сте Feast your eye on the new MAXeye collection, представляющем косметику «Мах Factor», окказиональное слово МАХеуе, очевидно, реферирует к торговой марке рекламируемого товара, тем самым акцентируя внимание читателя на коммерчески ключевой информации. В этой же нестандартной лексеме выявляется еще одна форма языковой девиации, также широко представленной в рекламе, - стилистический прием каламбура, или языковой игры. Образованный на основе единицы Max (разг. «максимальный»), окказионализм MAXеуе, декодируемый в контексте рекламы косметики для глаз, а именно теней для век, предназначенных для выделения и увеличения зоны глаз на лице женщины, может быть интерпретирован как «максимально увеличивающий глаз». Таким образом, МАХеуе возможно рассматривать как образец применения одновременно двух видов осознанных девиаций: окказионализма и каламбура.

7

Употребление каламбура в сфере рекламы максимально широко и разнообразно. Являясь наиболее эффективным в прагматическом плане и простым по механизмам образования средством создания юмористических и игровых форм дискурса, каламбур доминирует среди всех видов языковых девиаций в рекламе. Американский исследователь М. Моно, коллекционировавший и изучавший рекламные каламбуры на протяжении десяти лет, сравнил масштабы их распространения с «эпидемией, пронизавшей все американское общество» $[11$, с. 3].

Непосредственной реакцией рецептора на каламбур, как известно, является некая растерянность в связи с тем, что логический сценарий прочтения высказывания вдруг нарушается и в его семантическом поле образуются два дивергентных направления мысли, одинаково приемлемых для обозначенного контекста. Коммуникативным эффектом правильного прочтения такого смыслового диссонанса, как правило, бывает улыбка интерпретатора, смех или иная форма положительной эмоции, ассоциации, в конечном счете способствующие доброжелательному от- 
ношению потребителя к рекламируемому товару. Показательным в этом плане является пример рекламы автомобиля BMW Mini с открытым верхом: Let's always be open. Очевидно, что лексема ореn («открытый») одновременно реферирует и к параметрам рекламируемого типа автомобиля (кабриолет), и к поощряемой в западном обществе черте личности - открытости, правдивости. Оба эти значения, прямое и переносное, достаточно транспарентны и могут быть легко декодированы читателем в представленном каламбуpe, а игровая форма их включения обеспечит положительный рецептивный эффект. Прочтение «Давайте всегда стремиться к открытости (для чего следует покупать автомобили с открытым верхом)» будет успешной реализацией конечной цели этого рекламного продукта - убеждении потребителя в необходимости покупки рекламируемого товара.

Структурная независимость и дискурсивная мобильность каламбура способствуют тому, что он может возникать на любых языковых уровнях. Например, в рекламе автоответчика фирмы T.A.D. Avanti Inc. Find out what people called you используется фонетический каламбур: в зависимости от места логического ударения высказывание может быть прочитано и как «Узнайте, что за люди вам звонили», и как «Узнайте, как люди вас называли».

В рекламе товаров для оформления домашних интерьеров Everything your hearth desires эффектно использован морфологический каламбур, созданный путем игрового смешения двух графически схожих лексем: hearth («очаг») и heart («сердце»). Первый семантический план поддерживает рекламируемый товар, второй - апеллирует к хорошо известной фразе: Everything your heart desires («Bce, что вашей душе угодно»).

Примером синтаксического каламбура может служить реклама ряда рецептов с использованием яблок: An apple a day? Why stop at just one? («Каждый день по яблоку? А может быть, не будем ограничиваться только одним яблоком?»). Каламбур основан на игре прямого значения утверждения о необходимости этого продукта в представляемых рецептурных решениях блюд из яблок и переносного послания о полезности яблок в рационе человека. Прочтение переносного значения первого из двух вопросов становится возможным в ассоциации с известной английской поговоркой An apple a day keeps a doctor away («Каждый день по яблоку, и Вы избавлены от необходимости посещать доктора»). В результате применения каламбура в этом рекламном тексте потребитель сможет дешифровать имплицитное послание о том, что предлагаемые ему рецепты просты, а блюда, приготовленные по ним, полезны для его здоровья.

\section{8}

Стилистические диссонансы и стилевые контрасты выступают в роли еще одной разновидности осознанных языковых девиаций, которые также исполняют роль эффективного средства реализации основной функции рекламы - убедить в необходимости покупки товара.

По стилевому исполнению реклама представляет собой типичную разновидность гибридного дискурса, сочетающего в себе черты одновременно нескольких стилей: публицистического, научного, научно-популярного, отчасти разговорного и делового. Такое многообразие стилей в рекламе обусловлено прежде всего тем, что рекламодатель стремится вовлечь в состав целевой аудитории как можно более широкие массы потребителей. Кроме того, подобное нарушение языковых норм намеренно используется рекламным копирайтером для создания заданного коммуникативного эффекта.

Наиболее часто стилевые диссонансы и контрасты в рекламной словесности провоцируются путем включения в текст публицистического стиля разговорных элементов, которые создают специфическую тональность, напоминающую доверительный разговор с приятным собеседником. Элементы разговорной речи, намеренно включаемые в литературно выдержанный текст рекламного сообщения, используются в качестве инструмента «интимизации», создания дружеской атмосферы, располагающей потребителя к доверию и симпатии [6].

Явление стилевого диссонанса можно проследить на примере рекламного текста, 
представляющего новую модель автомобиля марки Крайслер: An American revolution. Just don't call it midsize to its face («Американская революция. Только не вздумайте говорить ему в лицо, что он средних размеров»). В этом рекламном тексте изначально заданный формальный стиль общения с читателем неожиданно прерывается неформальной речевой конструкцией, очевидно диссонирующей с исходным стилевым стандартом. В результате примененной стилевой девиации достигается искомый коммуникативный эффект - заинтересованность читателя, его дружелюбие, доверие к информации, поданной неформально, а также позитивный, игривый настрой, несомненно, увеличивающие шансы искомой реакции - приобретения товара.

Применение стилевого контраста в качестве девиации можно проследить на примере рекламы услуг туристического агентства «Australia.com», в которой наряду с вербальным наблюдается и визуальный диссонанс (см. рисунок).

Изначально заданный публицистический стиль текста согласуется как с языковыми нормами, так и с параязычной стилистикой ровные, строгие, упорядоченные линии, символизируют каноничность представляемого лингвистического и экстралингвистического пространства. Мелким шрифтом оформлены три фразы, описывающие заботу турагентства о своих клинетах: We've shampooed the camels («Мы вымыли шампунем верблюдов»). Laid on a nice sunset («Уложили прекрасный закат»). And the beer is waiting at the other end («И заготовили пиво в конце маршрута»). Неожиданно в размеренность языка, параязыка и иллюстрации (неспешно движущегося каравана с туристами) «врывается» маркированная фраза, построенная с нарушением языковых и параязыковых стандартов: So where the bloody hell are you? («Так где же вы, черт вас побери?»).

Неформальный текст с элементами сниженной лексики, в дополнение представленный в виде беспорядочных, асимметричных, небрежных графем, очевидно, символизирующих надпись, оставленную на песке раздраженным долгим ожиданием туроператором, выступают в качестве осознанных иррегуляций, нацеленных все на тот же коммуникативный эффект - возникновение симпатии и доверия со стороны потребителя к нестандартно транслируемым посылкам. Прагматический аспект использованных в этой рекламе девиаций видится также в том, что неформальный текст дан более крупным шрифтом, выполнен контрастно ярким цветом и располо-

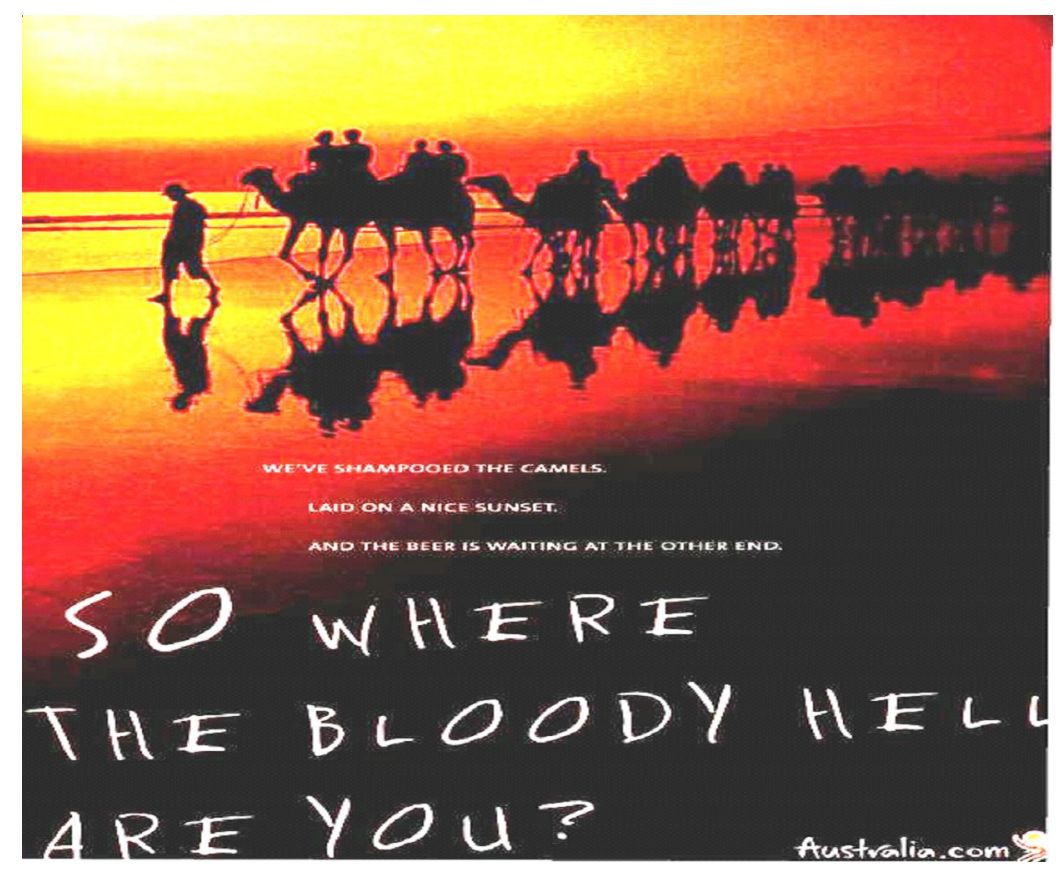

Реклама услуг туристического агентства «Australia.com»

Advertising of Australia.com tourist agency services 
жен в максимальной приближенности к взгляду читателя, символизируя тем самым ключевую значимость передаваемого ими послания. Наличие нескольких видов стилевого диссонанса в этом рекламном произведении и их очевидный коммуникативный эффект подтверждают масштабность и оправданность использования рекламой вербальных и невербальных аномалий в качестве успешных механизмов реализации заданных прагматических установок.

9

Рассматриваемое в целом коммуникативное пространство рекламного дискурса, в силу своей прагматики организованное так, чтобы быть броским, неожиданным, запоминающимся и убедительным, как известно, всегда отдает предпочтение нестандартным формам подачи ключевой информации. Ибо именно аномальные речевые единицы и модели, что было продемонстрировано выше, своей нестандартностью и энигматичностью как бы «случайно» нарушающие и «ломающие» языковые нормативы и дискурсивные регламенты, делая это зачастую в забавной и увлекательной форме, обеспечивают рекламе максимально эффективную реализацию ее основных коммуникативных (и следовательно, коммерческих) назначений.

Будучи ярким выразителем основных стратегий организации дискурса в сфере современной массовой коммуникации, реклама может рассматриваться как убедительное подтверждение того, насколько действенными способны быть речевые девиации в качестве механизмов реализации заданных прагматических установок.

Наличие большого количества таких аномалий в самых разных формах современного общественного дискурса на уровне лексики, грамматики, орфографии и стилистики также свидетельствует о достаточно либеральном отношении к ним со стороны современных языковых сообществ. Объяснение тому, очевидно, - в их мощном прагматическом потенциале и способности быть в высшей степени коммуникативно эффективными.

Учитывая эту особенность речевых аномалий, а также специфические тенденции в об- ласти социолингвистической организации современных обществ, можно предположить, что в ближайшем будущем девиативные процессы в речевых практиках языковых коллективов мира будут нарастать, а спектры их проникновения в область коммуникаций - расширяться.

\section{ПРИМЕЧАНИЕ}

${ }^{1}$ В языкознании под «девиацией» понимается «несоответствие правилам, заложенным в фактуальной языковой базе и в интуитивных речевых моделях носителей языка» [10, с. 288].

\section{СПИСОК ЛИТЕРАТУРЫ}

1. Ильинова, Е. Ю. Рекламный дискурс: ценности, образы, ассоциации / Е. Ю. Ильинова // Рекламный дискурс и рекламный текст / ред. Т. Н. Колокольцева. - М. : Флинта : Наука, 2011. - С. 38-56.

2. Кочетова, Л. А. Тенденции развития рекламного дискурса (на материале англоязычной рекламы) / Л. А. Кочетова // Рекламный дискурс и рекламный текст / ред. Т. Н. Колокольцева. - М. : Флинта : Наука, 2011. - С. 111-136.

3. Кудряшева, Ф. С. О языковой системе / Ф. С. Кудряшева // Вестник Челябинского государственного университета. Вып. 68. Филология. Искусствоведение. -2012. - № 21 (275). - С. 77-80.

4. Маковский, М. М. Лингвистическая комбинаторика. Опыт типологической стратификации языковых структур / М. М. Маковский. - М. : Наука, 1988. -232 c.

5. Ожегов, С. И. Лексикология. Лексикография. Культура речи / С. И. Ожегов // Работы по культуре речи. - М. : Высш. шк., 1974. - С. 276-285.

6. Почтарь, Е. И. Прагмастилистическая организация рекламы как дискурса убеждения (на материале американской печатной рекламы) : дис. ... канд. филол. наук / Почтарь Елена Ивановна. - М., 2011. -222 c.

7. Хомский, Н. Аспекты теории синтаксиса / Н. Хомский ; пер. В. Звегинцева. - М. : Изд-во Моск. ун-та, 1972. $-247 \mathrm{c}$.

8. Hymes, D. H. On communicative competence / D. H. Hymes // Sociolinguistics: selected readings / J. B. Pride, J. Holmes (eds.). - Harmondsworth : Penguin, 1972. - P. 269-293.

9. Hymes, D. H. Two types of linguistic relativity / D. H. Hymes // Sociolinguistics / ed. by W. Bright. The Hague : Mouton, 1966. - P. 114-158.

10. McArthur, T. The Oxford Companion to the English Language / T. McArthur. - N. Y. : Oxford University Press, 1992. -1184 p. 
11. Monnot, M. Selling America. Puns, language, and Advertising / M. Monnot. - Washington, DC : University Press of America, 1981. - 125 p.

\section{REFERENCES}

1. Ilyinova E.Yu. Reklamnyy diskurs: tsennosti, obrazy, assotsiatsii [Advertising Discourse: Values, Images, Associations]. Kolokoltseva T.N., ed. Reklamnyy diskurs i reklamnyy tekst [Advertising Discourse and Advertising Text]. Moscow, Flinta Publ.; Nauka Publ., 2011, pp. 38-56.

2. Kochetova L.A. Tendentsii razvitiya reklamnogo diskursa (na materiale angloyazychnoy reklamy) [Tendencies in Advertising Discourse Development (on the basis of English-Language Advertising)]. Kolokoltseva T.N., ed. Reklamnyy diskurs i reklamnyy tekst [Advertising Discourse and Advertising Text]. Moscow, Flinta Publ.; Nauka Publ., 2011,pp. 111-136.

3. Kudryasheva F.S. O yazykovoy sisteme [On the Language System]. Vestnik Chelyabinskogo gosudarstvennogo universiteta. Vyp. 68, Filologiya. Iskusstvovedenie, 2012, no. 21 (275), pp. 77-80.

4. Makovsky M.M. Lingvisticheskaya kombinatorika. Opyt tipologicheskoy stratifikatsii yazykovykh struktur [Linguistic Combinatorics.
Language Structures Topologic Stratification Experience]. Moscow, Nauka Publ., 1988. 232 p.

5. Ozhegov S.I. Leksikologiya. Leksikografiya. Kultura rechi [Lexicology. Lexicography. Speech Culture]. Raboty po kulture rechi [Works on Speech Culture]. Moscow, Vysshaya shkola Publ., 1974, pp. 276-285.

6. Pochtar E.I. Pragmastilisticheskaya organizatsiya reklamy kak diskursa ubezhdeniya (na materiale amerikanskoy pechatnoy reklamy): dis. ... kand. filol. nauk [Pragmastylistic Arrangement of Advertising as a Persuasive Discourse (based on American Print Advertising). Cand. philol. sci. diss.]. Moscow, 2011. 222 p.

7. Chomsky N. Aspekty teorii sintaksisa [Aspects of the Theory of Syntax]. Moscow, Izd-vo Moskovskogo universiteta, 1972. $247 \mathrm{p}$.

8. Hymes Dell H. On communicative competence. Pride J.B., Holmes J., eds. Sociolinguistics: selected readings. Harmondsworth, Penguin, 1972, pp. 269-293.

9. Hymes Dell H. Two types of linguistic relativity. Bright W., ed. Sociolinguistics. The Hague, Mouton, 1966, pp. 114-158.

10. McArthur Tom. The Oxford Companion to the English Language. New York, Oxford University Press, 1992. 1184 p.

11. Monnot M. Selling America. Puns, language and Advertising. Washington, DC, University Press of America, Inc., 1981. 125 p.

\section{Information About the Author}

Elena I. Pochtar, Candidate of Sciences (Philology), Associate Professor, Head of Department of Translation Theory and Practice, Pridnestrovian State University named after T.G. Shevchenko, 25-go Oktyabrya St., 107, 3300 Tiraspol, Pridnestrovian Moldavian Republic, ent_15@rambler.ru.

\section{Информация об авторе}

Елена Ивановна Почтарь, кандидат филологических наук, доцент, заведующая кафедрой теории и практики перевода, Приднестровский государственный университет им. Т.Г. Шевченко, ул. 25-го Октября, 107, 3300 г. Тирасполь, Приднестровье, ent_15@rambler.ru. 